(2) Open Access Full Text Article

\title{
Dose-proportional pharmacokinetic properties of GLA5PR GLARS-NFI controlled-release pregabalin in healthy Korean volunteers: a randomized, open, single-dose, parallel study
}

This article was published in the following Dove Press journal:

Drug Design, Development and Therapy

\begin{abstract}
Kwang-Hee Shin'
Ji-Young Jeon ${ }^{2}$

Kyungho Jang ${ }^{2}$

Tae-Eun $\mathrm{Kim}^{3}$

Min-Gul Kim ${ }^{2,4}$

'College of Pharmacy, Research Institute of Pharmaceutical Sciences, Kyungpook National University, Daegu, Republic of Korea; ${ }^{2}$ Center for Clinical Pharmacology and Biomedical Research Institute, Chonbuk National University Hospital, Jeonju, Republic of Korea; ${ }^{3}$ Department of Clinical Pharmacology, Konkuk University Medical Center, Seoul, Republic of Korea; ${ }^{4}$ Department of Pharmacology, School of Medicine, Chonbuk National University, Jeonju, Republic of Korea
\end{abstract}

Correspondence: Min-Gul Kim Department of Pharmacology, School of Medicine, Chonbuk National University, 20, Geonji-ro, Deokjin-Gu, Jeonju, Jeollabuk-do 54907, Republic of Korea Tel +820632593480

Email mgkim@jbnu.ac.kr

\begin{abstract}
Purpose: The aim of this study was to evaluate the dose-proportional pharmacokinetic characteristics of pregabalin following the administration of GLA5PR GLARS-NF1 tablets (150, 300,450 , and $600 \mathrm{mg}$ ) in the fed state.

Subjects and methods: An open-label, randomized, single-dose, parallel study was conducted in 40 eligible subjects who were randomly assigned to receive a single $150,300,450$, or $600 \mathrm{mg}$ dose of GLA5PR GLARS-NF1. Serial blood samples were collected before and after dosing for 36 hours, and plasma concentrations were determined using liquid chromatography-tandem mass spectrometry. Safety profiles were evaluated throughout the study (trial registration number: NCT02327000).
\end{abstract}

Results: Thirty-seven subjects completed the studies. The area under the plasma concentrationtime curve up to the last measurable concentration of pregabalin exhibited dose proportionality following administration of GLA5PR GLARS-NF1 tablets from 150 to $600 \mathrm{mg}$ while its maximum plasma concentration showed dose proportionality at a dose range of $150-450 \mathrm{mg}$. The safety evaluations showed no clinically significant finding after administration of GLA5PR GLARS-NF1 tablets $(150,300,450$, and $600 \mathrm{mg})$ in the fed state.

Conclusions: The dose-proportional properties of GLA5PR GLARS-NF1 150-450 mg tablets were determined.

Keywords: gamma-aminobutyric acid analog, GABA analog, maximum concentration, safety evaluation, Korean

\section{Introduction}

Pregabalin, a gamma-aminobutyric acid (GABA) analog, acts similarly to $\left[{ }^{3} \mathrm{H}\right]$-gabapentin by binding to the $\alpha_{2} \delta$ protein of voltage-gated calcium channels in the central nervous system. ${ }^{1}$ It is used as a treatment for neuropathic pain (particularly diabetic neuropathic pain and herpetic neuralgia) and fibromyalgia and as a supplementary treatment for epilepsy (partial seizure). ${ }^{2,3}$ Lyrica $^{\circledR}$ capsules (Pfizer Pharmaceutical Ltd., Ann Arbor, MI, USA), the first pregabalin preparation, are manufactured as various dosage formulations, from 25 to $300 \mathrm{mg}$. The recommended doses of pregabalin are different from the indications. For example, $75-150 \mathrm{mg}(150-300 \mathrm{mg} /$ day) two times a day or 50-100 $\mathrm{mg}$ three times a day (150-300 $\mathrm{mg} /$ day) is recommended for postherpetic neuralgia and 300-450 mg/day is recommended for fibromyalgia. ${ }^{4}$ Pregabalin is recommended as a twice daily dosing regimen, with 75-300 $\mathrm{mg}$ recommended for oncedaily dosing. ${ }^{1}$ It is absorbed into the systemic circulation in a dose-dependent manner. 
The blood concentration of pregabalin has been reported to peak 1 hour after dosing and decrease with an elimination half-life $\left(t_{1 / 2}\right)$ of 4.8-6.3 hours..$^{5}$ Therefore, pregabalin was developed to be administered three times daily. ${ }^{6}$ Subsequently, a twice daily formulation was also developed and marketed after testing in clinical trials. ${ }^{7,8}$

The Geometrically Long Absorption Regulated System $\left(\right.$ GLARS $^{\circledR}$ ) developed by GL Pharm Tech Corporation (Seongnam, Gyeonggi-do, Republic of Korea) is a technology used to produce a unique three-layered, sustained-release tablet. The upper and lower layers contain polymers that rapidly swell and absorb an aqueous medium following contact. The middle layer contains highly hydrophilic excipients that help the medium penetrate the tablet's interior rapidly. GLARS produces a tablet that the middle layer rapidly absorbs medium to dissolve the ingredients and the upper and lower layers swell to extend drug release. ${ }^{9}$ The swollen polymer simultaneously collapses the sides of the middle layer to control the release rate of the drug. Conversely, the relatively robust swelling layer reduces the external physical effects, such as those of the intestinal movement, on the drug release rate. The tablet absorbs approximately three to five times its weight in excess medium, which causes the tablet to continue releasing the drug even in the colon, where lack of aqueous medium exists to induce drug release. This technology has paved the way for developing once daily, sustainedrelease drug formulations with specific characteristics that were previously unachievable.

The GLA5PR GLARS-NF1 $150 \mathrm{mg}$ tablet is a GLARSadapted formulation of pregabalin developed by the GL Pharm Tech Corporation as a once daily regimen. It is a three-layered tablet with an uneven distribution of pregabalin in each layer. The upper and lower layers contain the high viscosity polymer, $\mathrm{PEO}$, which regulates the release rate of pregabalin. In a previous study to compare the pharmacokinetic (PK) properties of GLA5PR GLARS-NF1 tablet and an immediate release (IR) formulation (Lyrica capsule, Pfizer) after multiple dosing under fed conditions in healthy male subjects (ClinicalTrials.gov registry no: NCT01638273), the maximum plasma concentration $\left(C_{\max }\right)$ at the steady state of pregabalin was $27.74 \%$ higher following the administration of GLA5PR GLARS-NF1 tablet $150 \mathrm{mg}$ than when the IR formulation ( $75 \mathrm{mg}$, twice daily $=150 \mathrm{mg} /$ day) was administered, whereas the area under the plasma concentrationtime curve (AUC) at the steady state of pregabalin after repeated administration to fed healthy male subjects was bioequivalent between the GLA5PR GLARS-NF1 $150 \mathrm{mg}$ tablet and the immediate formulation. Repeated treatment with GLA5PR GLARS-NF1 was determined to be tolerable in healthy subjects compared with the immediate formulation.

This study was performed to evaluate the PK characteristics and the dose proportionality of pregabalin following the administration of GLA5PR GLARS-NF1 tablets (150, 300, 450 , and $600 \mathrm{mg}$ ) in the fed state for clinical development.

\section{Subjects and methods Subjects, ethics approval, and consent to participate}

Healthy Korean male volunteers aged over 19-45 years were eligible for inclusion in this study if they weighed $\geq 45 \mathrm{~kg}$ and had a body mass index (BMI) of $17.5-30.5 \mathrm{~kg} / \mathrm{m}^{2}$. Subjects were excluded from the study if they had any evidence or history of clinically significant diseases or an abnormal laboratory test result of clinical biochemistry, hematology, or urinalysis.

Study subjects were prohibited from consuming caffeinated or alcoholic beverages, smoking, and exercising strenuously from 3 days before study drug administration to the end of the last study period. Subjects were hospitalized from 9 hours before receiving the study drug to 36 hours after dosing. All subjects were fed a standard meal at 7:30 pm within 20 minutes on the day of administration of the investigational drug for each period followed by oral administration of either one tablet each of the test or reference drug according to the randomly assigned sequence at approximately 8:00 pm.

All subjects provided their written informed consent before being screened for the study. The study protocols were reviewed and approved by the Institutional Review Board of Chonbuk National University Hospital (ClinicalTrials.gov registry no: NCT02327000). These studies were conducted at Chonbuk National University Hospital, Center of Clinical Pharmacology, Republic of Korea. The studies were conducted in accordance with the principles stipulated in the Declaration of Helsinki, as amended in 2013 (Fortaleza, Brazil) and the Good Clinical Practice guidelines of the International Council for Harmonization.

\section{Study design and treatment}

The study was conducted as a randomized, open-label, singledose parallel study in 40 healthy male volunteers who were assigned to four treatment groups of 10 subjects each. The investigational products were GLA5PR GLARS-NF1 tablets (150 mg) and GLA5PR GLARS-NF1 tablets (300 mg). Four treatment groups were assigned as follows: treatment 1, single administration of GLA5PR GLARS-NF1 $150 \mathrm{mg}$; treatment 2, single administration of GLA5PR GLARS-NF1 $300 \mathrm{mg}$; treatment 3, single administration of GLA5PR 
GLARS-NF1 $450 \mathrm{mg}$ (150 mg tablet+300 mg tablet); and treatment 4 , single administration of GLA5PR GLARS-NF1 $600 \mathrm{mg}$ (two $300 \mathrm{mg}$ tablets).

The investigational product was administered orally in the fed state at approximately 8:00 pm according to treatment groups. The consumption of a standard meal began 30 minutes prior to drug administration (approximately 7:30 pm) and finished within 20 minutes. The standard meal contained $2,000 \mathrm{kcal} / \mathrm{day}$, with a caloric content of carbohydrates $255 \mathrm{~g} /$ day, protein $95 \mathrm{~g} /$ day, and lipids $60 \mathrm{~g} /$ day, which served as a general meal to patients in the Chonbuk National University Hospital. Subjects swallowed the investigational product as a whole tablet with $240 \mathrm{~mL}$ of water and did not chew the medication prior to swallowing. The oral cavity of each subject was examined by the investigator following dosing to ensure that the investigational product had been administered.

\section{Determination of plasma pregabalin concentration}

We used a standard procedure for the sample preparation. Following a single dose of GLA5PR GLARS-NF1, blood samples were collected before dosing ( 0 hour) and 1, 1.5, 2, $3,4,5,6,8,10,12,14,24$, and 36 hours after dosing of the drug for the PK analysis.

A validated liquid chromatography-tandem mass spectrometry (LC-MS/MS) method was used to analyze the samples, ${ }^{10}$ and pregabalin- ${ }^{13} \mathrm{C}_{3}$ was used as the internal standard. Human plasma was pretreated with pregabalin using a protein precipitation method, and the suitability of the linearity and quality control samples of each batch was evaluated. The calibration curve was constructed using a concentration range of 50-20,000 ng/mL in plasma, and the correlation coefficient $(r)$ value was $>0.9950$. In addition, the accuracy of the low-, medium-, and high-concentration control samples was evaluated to confirm the suitability of the analysis of batch and measurement values. The accuracies ranged between $85 \%$ and $115 \%$ (85\% and $120 \%$ for the lower limit of quantification), and the precisions were $<15 \%$. The change $(\%)$ of the stabilities of the stock and standard solutions between the reference and the test samples were confirmed to be within $10 \%$. The concentration of pregabalin in the sample was obtained by calculating the peak area ratio of the analyte to the peak area of each internal standard material obtained after the LC-MS/MS analysis.

\section{PK analysis}

The plasma concentrations of pregabalin at scheduled time points following drug administration were analyzed. The PK parameters for each treatment group were analyzed: $C_{\max }$, the time required to reach the $C_{\max }\left(T_{\max }\right)$, AUC from 0 hour to time $t\left(\mathrm{AUC}_{0-t}\right.$, where $t$ is the last time point with a measurable concentration), AUC from 0 hour to infinity ( $\mathrm{AUC}_{0 \text {-inf }}$ ), and $t_{1 / 2}$. The $\mathrm{AUC}_{0-\mathrm{t}}$ was calculated using the linear trapezoidal method. The observed concentrations and times were used to estimate the $C_{\max }$ and $T_{\max }$ of pregabalin. The $\mathrm{AUC}_{0-\text { inf }}$ was calculated as $\mathrm{AUC}_{0-\mathrm{t}}+C_{\mathrm{t}} / \lambda_{\mathrm{z}}$, where $C_{\mathrm{t}}$ is the last measured concentration, and $\lambda_{\mathrm{z}}$ is the elimination rate constant calculated using linear regression of the log-linear portion of the plasma concentration-time curve. The $t_{1 / 2}$ was calculated as $\ln ^{2} / \lambda_{\mathrm{z}}$. All the PK parameters were estimated using the Phoenix $^{\circledR}$ WinNonlin ${ }^{\circledR}$ software (version 6.3, Certara USA Inc., Princeton, NJ, USA).

\section{Tolerability assessment}

The tolerability was assessed by the investigator who monitored adverse events (AEs) and vital signs and performed physical examinations, 12-lead electrocardiogram (ECG), and clinical laboratory tests. Full physical examinations were conducted at the screening, and poststudy visit and brief physical examinations were performed on day 1 and day 3 of the study period. ECGs were performed at the screening and poststudy visit. Vital signs were evaluated at screening, day 1 and day 3 of the study period, and the poststudy visit. Systolic and diastolic blood pressures and heart rate were measured in subjects in a sitting position after a 3-minute rest using an automated device. The body temperature was measured using a tympanic thermometer. Blood samples were collected for clinical laboratory assessments of hematology and blood chemistry, and urinalysis was conducted at screening and on day 1 and day 3 of the study period and the poststudy visit.

\section{Statistical analysis}

The PK parameters were descriptively analyzed and summarized as the arithmetic mean and standard deviation (SD) or the median and range for the $T_{\max }$. The PK parameters and dose-normalized $C_{\max }$ and $\mathrm{AUC}_{\text {last }}$ were compared among the groups using a one-way ANOVA. The dose-normalized $C_{\max }$ and $\mathrm{AUC}_{\text {last }}$ of the 300, 450, and $600 \mathrm{mg}$ treatment groups were compared with those of the $150 \mathrm{mg}$ treatment group. Geometric least square mean ratios and $90 \%$ CIs of the 300 , 450 , and $600 \mathrm{mg}$ treatment groups compared with those of the $150 \mathrm{mg}$ treatment group were evaluated. The $C_{\max }$ and $\mathrm{AUC}_{\text {last }}$ were tested using linear regression analysis, setting the administered dose as the independent variable and primary PK variables $\left(C_{\max }\right.$ and $\left.\mathrm{AUC}_{\text {last }}\right)$ as dependent variables. Power model $\left[\mathrm{Y}=\operatorname{Exp}(\alpha)(\operatorname{Dose})^{\wedge} \beta \operatorname{Exp}(\varepsilon)\right]$ was used in this 
analysis. $\ln (Y)=\alpha+\beta \cdot \ln ($ Dose $)+\varepsilon$, where $\alpha$ represents fixed period effects and random subject effects, $\beta$ equal to 1 indicates perfect dose proportionality, and $\varepsilon$ represents errors. ${ }^{11}$

Dose proportionality was determined when the $(1-\alpha) \times 100 \%$ CI of slope $\beta$ fell within the equivalent limit. ${ }^{12}$ The $\Theta$ was a prespecified limit; $\Theta_{L}$ was 0.8 as the low limit and $\Theta_{\mathrm{H}}$ was 1.25 as the high limit. The $r$ was 4 as the ratio of the highest to the lowest dose. ${ }^{12}$

Equivalent limits: $1+\frac{\ln \left(\theta_{L}\right)}{\ln (r)}<\beta<1+\frac{\ln \left(\theta_{H}\right)}{\ln (r)}$

The statistical analysis was performed using the $\mathrm{SAS}^{\circledR}$ software version 9.4 (SAS Institute Inc., Cary, NC, USA).

\section{Results}

\section{Subjects}

A total of 40 subjects were enrolled and randomized (10 per treatment group). Two subjects withdrew their consent before administration of the investigational product, and 38 subjects were administered the investigational product. One subject dropped out of the study after completing the scheduled blood sampling. Although the poststudy visit was missed, the subject was included in the PK data set. Finally, 37 subjects completed the study according to the study protocol and, therefore, the PK analysis was performed in 38 subjects. All the subjects were healthy male volunteers with a mean age, height, weight, and BMI of 24.7 years, $173.59 \mathrm{~cm}, 71.24 \mathrm{~kg}$, and $23.62 \mathrm{~kg} / \mathrm{m}^{2}$, respectively (Table 1 ).

These demographics were not significantly different among the treatment groups. Histories of smoking cigarettes and consumption of alcohol and caffeine were recorded during the screening interview, and all subjects met the inclusion criteria. There were no statistically significant differences among treatment groups in the cigarette smoking and alcohol consumption history. There was a statistically significant difference among treatment groups in caffeine intake $(P=0.0434)$. However, caffeine intake was assessed at screening and it was prohibited during hospitalization. Moreover, the half-life of caffeine was reported to be approximately $15-45$ minutes, ${ }^{13}$ and no significant interaction between pregabalin and caffeine was reported. Thus, this outcome was not considered to have affected the results of the study.

\section{PK analysis}

The plasma pregabalin concentration-time profiles after GLA5PR GLARS-NF1 150, 300, 450, and 600 mg administration are presented in Figure 1. The PK parameters of each treatment are described in Table 2 . There were no statistically significant differences between treatment groups in the dosenormalized $C_{\max }(P=0.5962)$ and $\mathrm{AUC}_{\text {last }}(P=0.9874)$. The geometric mean ratios and $90 \% \mathrm{CIs}$ for the dose-corrected $C_{\text {max }}$ and $\mathrm{AUC}_{\text {last }}$ are presented in Table 3.

The comparison between treatments 1 and 2 (GLA5PR GLARS-NF1 $150 \mathrm{mg}$ and $300 \mathrm{mg}$, respectively) revealed that the geometric mean ratios ( $90 \% \mathrm{CIs})$ of $C_{\max }$ and $\mathrm{AUC}_{\text {last }}$ were 0.9767 (0.8416-1.1335) and 1.0205 (0.8928-1.1666), respectively. The comparison between treatments 1 and 3 (GLA5PR GLARS-NF1 100 and $450 \mathrm{mg}$, respectively) showed that the geometric mean ratios ( $90 \% \mathrm{CIs}$ ) of $C_{\max }$ and $\mathrm{AUC}_{\text {last }}$ were 0.9389 (0.8057-1.0941) and 0.9908 (0.8636-1.1368), respectively. The comparison between treatments 1 and 4 (GLA5PR GLARS-NF1 100 and $600 \mathrm{mg}$, respectively) revealed that the geometric mean ratios $(90 \%$ CIs) of $C_{\max }$ and $\mathrm{AUC}_{\text {last }}$ were 0.8949 (0.7680-1.0429) and 1.0139 (0.8838-1.1632), respectively (Table 3). The median and distribution of $C_{\max }$ and $\mathrm{AUC}_{\text {last }}$ data in each treatment were analyzed. Both the $C_{\max }$ and $\mathrm{AUC}_{\text {last }}$ of treatment 1 (GLA5PR GLARS-NF1 $150 \mathrm{mg}$ ) showed relatively wide ranges of individual variability compared with those of the other treatments (Figure 2A and B).

Table I Demographic data of the 38 study subjects

\begin{tabular}{|c|c|c|c|c|c|c|}
\hline \multirow[t]{2}{*}{ Variable } & \multicolumn{4}{|c|}{ Treatment groups } & \multirow{2}{*}{$\begin{array}{l}\text { All subjects } \\
(\mathrm{N}=38)\end{array}$} & \multirow[t]{2}{*}{$P$-value } \\
\hline & $\begin{array}{l}150 \mathrm{mg} \\
(\mathrm{n}=10)\end{array}$ & $\begin{array}{l}300 \mathrm{mg} \\
(\mathrm{n}=10)\end{array}$ & $\begin{array}{l}450 \mathrm{mg} \\
(\mathrm{n}=9)\end{array}$ & $\begin{array}{l}600 \mathrm{mg} \\
(\mathrm{n}=9)\end{array}$ & & \\
\hline Age (years) & $24.9 \pm 2.5$ & $23.8 \pm 1.6$ & $25.3 \pm 1.5$ & $24.8 \pm 3.5$ & $24.7 \pm 2.4$ & 0.5570 \\
\hline Weight (kg) & $74.44 \pm 8.67$ & $68.58 \pm 6.85$ & $70.76 \pm 4.81$ & $71.11 \pm 11.87$ & $71.24 \pm 8.36$ & 0.4893 \\
\hline Height $(\mathrm{cm})$ & $175.89 \pm 5.18$ & $173.06 \pm 5.96$ & $173.14 \pm 3.86$ & $172.08 \pm 7.26$ & $173.59 \pm 5.65$ & 0.5008 \\
\hline BMI $\left(\mathrm{kg} / \mathrm{m}^{2}\right)$ & $24.14 \pm 3.48$ & $22.88 \pm 1.70$ & $23.60 \pm 1.61$ & $23.87 \pm 2.15$ & $23.62 \pm 2.33$ & 0.6751 \\
\hline
\end{tabular}

Notes: Treatment I (I50 mg): GLA5PR GLARS-NFI 150 mg tablet; treatment 2 (300 mg): GLA5PR GLARS-NFI 300 mg tablet; treatment 3 (450 mg): GLA5PR GLARS-NFI 150 mg+300 mg tablets; treatment $4(600 \mathrm{mg})$ : GLA5PR GLARS-NFI two $300 \mathrm{mg}$ tablets; all treatments were after standard meal. aNOVA was used. Data are presented as mean \pm standard deviation.

Abbreviation: BMI, body mass index. 

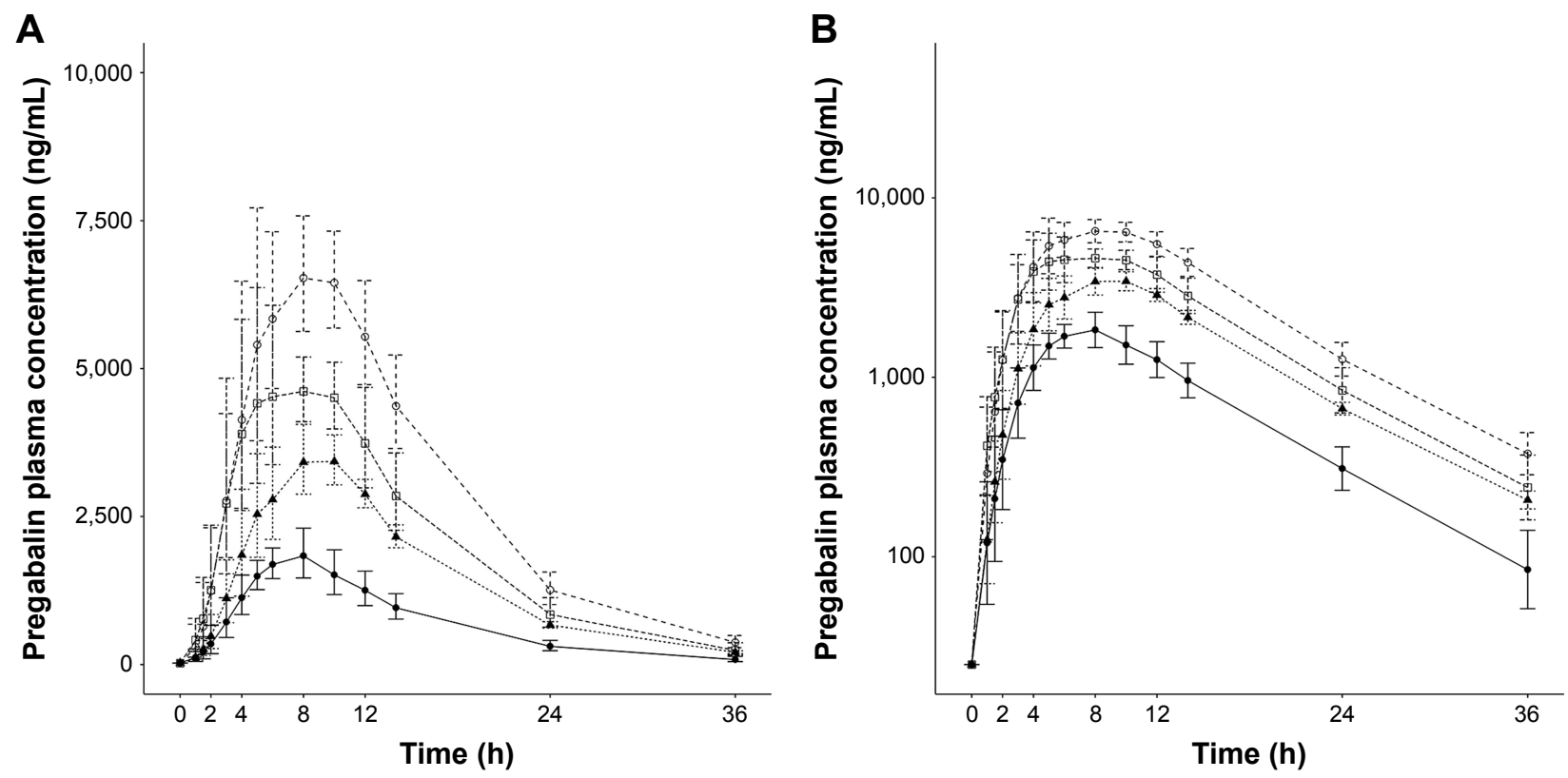

- GLA5PR GLARS-NF1 tablet $150 \mathrm{mg}$ single administration (after standard meal)
- - - GLA5PR GLARS-NF1 tablet $300 \mathrm{mg}$ single administration (after standard meal)
- - GLA5PR GLARS-NF1 $450 \mathrm{mg}$ (300 mg 1 tablet + $150 \mathrm{mg} 1$ tablet) single administration (after standard meal)
- GLA5PR GLARS-NF1 $600 \mathrm{mg}$ (300 mg 2 tablets) single administration (after standard meal)

Figure I Mean plasma concentration-time curves of pregabalin by treatment groups. Note: (A) Linear and (B) log scale.

In the analysis of dose proportionality using the power model, the $90 \% \mathrm{CI}$ of $C_{\max }$ and $\mathrm{AUC}_{\text {last }}$ was $0.8241-1.0252$ and $0.9130-1.0935$, respectively. Furthermore, the values of $\mathrm{AUC}_{\text {last }}$ fell within the equivalent limit of 0.8390-1.1610, which demonstrated dose proportionality, but those of $C_{\text {max }}$ did not (Table 4). Regressions for $\log ($ dose $)$ vs $\log \left(C_{\max }\right)$ and $\log A U C\left({ }_{\text {last }}\right)$ of each individuals by treatment group are presented in Figure 3A and B, respectively.

\section{Tolerability}

Among the 38 subjects who received the investigational products, 10 experienced $17 \mathrm{AEs}$ (treatment 1 , one $\mathrm{AE}$ in one subject; treatment 2, three AEs in three subjects; treatment 3: four AEs in two subjects; and treatment 4, nine AEs in four subjects) (Table 5). Six cases of dizziness; two cases of blurred vision, white blood cells in the urine, dysarthria, and headache; and one case of blood bilirubin increase, nausea,

Table 2 Summary of plasma pregabalin pharmacokinetic parameter values after oral administration of GLA5PR GLARS-NFI I50, 300, 450 , and $600 \mathrm{mg}$

\begin{tabular}{|c|c|c|c|c|c|}
\hline \multirow[t]{2}{*}{ Variable } & \multicolumn{4}{|l|}{ Treatment groups } & \multirow[t]{2}{*}{$P$-value ${ }^{a}$} \\
\hline & 150 mg $(n=10)$ & $300 \mathrm{mg}(\mathrm{n}=10)$ & $450 \mathrm{mg}(\mathrm{n}=9)$ & $600 \mathrm{mg}(\mathrm{n}=9)$ & \\
\hline $\mathrm{AUC}_{\text {last }}\left(\mathrm{h} \cdot \mathrm{ng}^{-1} \cdot \mathrm{mL}^{-1}\right)$ & $26,439.53 \pm 5,606.82$ & $52,995.99 \pm 5,916.89$ & $77,632.88 \pm 12,525.10$ & $106,053.94 \pm 17,346.78$ & $<0.001$ \\
\hline $\mathrm{AUC}_{\text {last }} /$ dose $\left(\mathrm{h} \cdot \mathrm{ng}^{-1} \cdot \mathrm{mL}^{-1} \cdot \mathrm{mg}^{-1}\right)$ & $176.26 \pm 37.38$ & $176.65 \pm 19.72$ & $172.52 \pm 27.83$ & $|76.76 \pm 28.9|$ & 0.9874 \\
\hline$A \cup C_{i n f}\left(h \cdot n g^{-1} \cdot m L^{-1}\right)$ & $27,658.58 \pm 5,798.22$ & $54,928.06 \pm 5,986.83$ & $80,448.20 \pm 14,894.16$ & $109,729.69 \pm 18,694.32$ & $<0.001$ \\
\hline$C_{\max }(\mathrm{ng} / \mathrm{mL})$ & $2,063.04 \pm 436.24$ & $3,975.90 \pm 539.13$ & $5,799.61 \pm 1,213.89$ & $7,342.02 \pm 1,374.87$ & $<0.001$ \\
\hline$C_{\max } /$ dose $\left(\mathrm{ng} \cdot \mathrm{mL}^{-1} \cdot\right.$ dose $\left.^{-1}\right)$ & $13.75 \pm 2.9 \mid$ & $13.25 \pm 1.80$ & $12.89 \pm 2.70$ & $12.24 \pm 2.29$ & 0.5962 \\
\hline$T_{\max }(\mathrm{h})$ & $6.00[4.00-8.00]$ & $8.00[5.00-12.0]$ & $6.00[4.00-12.0]$ & $8.00[4.00-10.0]$ & NA \\
\hline$t_{1 / 2}(\mathrm{~h})$ & $6.5 I \pm 0.89$ & $6.37 \pm 0.33$ & $6.23 \pm 0.85$ & $6.23 \pm 0.69$ & 0.804 \\
\hline $\mathrm{CL} / \mathrm{F}(\mathrm{L} / \mathrm{h})$ & $5.69 \pm 1.44$ & $5.52 \pm 0.59$ & $5.75 \pm 1.00$ & $5.62 \pm 1.03$ & 0.968 \\
\hline $\mathrm{Vd} / \mathrm{F}(\mathrm{L})$ & $52.24 \pm 9.29$ & $50.74 \pm 5.98$ & $50.98 \pm 6.52$ & $50.10 \pm 8.21$ & 0.940 \\
\hline
\end{tabular}

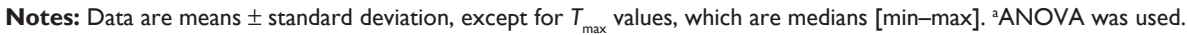

Abbreviations: $A \cup C_{\text {last }}$, area under the serum concentration-time curve from time zero to the time of the last measured concentration; $C_{\text {max }}$, maximum serum concentration; $T_{\text {max }}$, time to peak concentration; $t_{1 / 2}$, half-life; CL/F, apparent clearance; Vd/F, apparent volume of distribution; NA, not applicable. 
Table 3 Statistical analysis of dose proportionality of dose-normalized data using $\mathrm{Cl}$ approach base on ANOVA model

\begin{tabular}{|c|c|c|c|c|}
\hline \multirow[t]{2}{*}{ Pharmacokinetic parameter } & \multicolumn{2}{|c|}{ Geometric LSM } & \multicolumn{2}{|c|}{ Geometric LSM ratio } \\
\hline & $\begin{array}{l}300 \mathrm{mg} \\
(\mathrm{n}=10)\end{array}$ & $\begin{array}{l}150 \mathrm{mg} \\
(\mathrm{n}=10)\end{array}$ & $\begin{array}{l}\text { Point estimate } \\
(300 / 150 \mathrm{mg})\end{array}$ & $90 \% \mathrm{Cl}$ \\
\hline $\mathrm{AUC}_{\text {last }} /$ dose $\left(\mathrm{h} \cdot \mathrm{ng}^{-1} \cdot \mathrm{mL}^{-1} \cdot \mathrm{mg}^{-1}\right)$ & 175.67 & 172.14 & 1.0205 & $0.8928-1.1666$ \\
\hline \multirow{2}{*}{$C_{\max } /$ dose $\left(\mathrm{ng} \cdot \mathrm{mL}^{-1} \cdot \mathrm{mg}^{-1}\right)$} & 13.14 & 13.45 & 0.9767 & $0.8416-1.1335$ \\
\hline & $\begin{array}{l}450 \mathrm{mg} \\
(\mathrm{n}=9)\end{array}$ & $\begin{array}{l}150 \mathrm{mg} \\
(\mathrm{n}=10)\end{array}$ & $\begin{array}{l}\text { Point estimate } \\
\text { (450/150 mg) }\end{array}$ & $90 \% \mathrm{Cl}$ \\
\hline $\mathrm{AUC}_{\text {last }} /$ dose $\left(\mathrm{h} \cdot \mathrm{ng}^{-1} \cdot \mathrm{mL}^{-1} \cdot \mathrm{mg}^{-1}\right)$ & 170.56 & 172.14 & 0.9908 & $0.8636-1.1368$ \\
\hline \multirow{2}{*}{$C_{\max } /$ dose $\left(\mathrm{ng} \cdot \mathrm{mL}^{-1} \cdot \mathrm{mg}^{-1}\right)$} & 12.63 & 13.45 & 0.9389 & $0.8057-1.094 \mid$ \\
\hline & $\begin{array}{l}600 \mathrm{mg} \\
(\mathrm{n}=9)\end{array}$ & $\begin{array}{l}150 \mathrm{mg} \\
(\mathrm{n}=10)\end{array}$ & $\begin{array}{l}\text { Point estimate } \\
\text { (600//50 mg) }\end{array}$ & $90 \% \mathrm{Cl}$ \\
\hline $\mathrm{AUC}_{\text {last }} /$ dose $\left(\mathrm{h} \cdot \mathrm{ng}^{-1} \cdot \mathrm{mL}^{-1} \cdot \mathrm{mg}^{-1}\right)$ & 174.55 & 172.14 & 1.0139 & $0.8838-1.1632$ \\
\hline$C_{\max } /$ dose $\left(\mathrm{ng} \cdot \mathrm{mL}^{-1} \cdot \mathrm{mg}^{-1}\right)$ & 12.04 & 13.45 & 0.8949 & $0.7680-1.0429$ \\
\hline
\end{tabular}

Abbreviations: $A \cup C_{\text {last }}$, area under the serum concentration-time curve from time zero to the time of the last measured concentration; $C_{\text {max }}$, maximum serum concentration; LSM, least square mean.

and hypertension were reported. Four cases of dizziness, two cases of blurred vision and dysarthria, and one case of nausea were moderate in intensity, and the other eight AEs were mild in intensity.

Six cases of dizziness, two cases of blurred vision, dysarthria and headache, and one case of nausea were considered to be related to the investigational product. Other AEs were not considered to have causal relationships with the investigational products. For all AEs, no action was taken, and subjects recovered without any sequelae. No clinically significant findings were observed in the safety evaluations of the laboratory tests, vital signs, physical examinations, and ECGs.

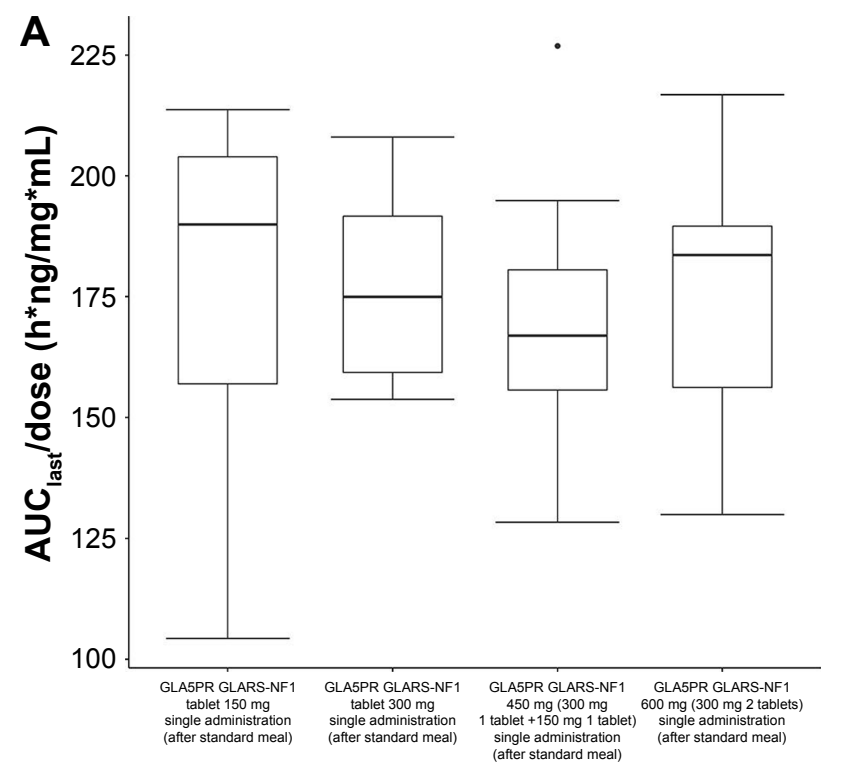

\section{Discussion}

This study aimed to evaluate the PK characteristics of pregabalin following the administration of GLA5PR GLARS-NF1 tablets $(150,300,450$, and $600 \mathrm{mg})$ in the fed state. GLA5PR GLARS-NF1 exhibited dose linearity in the range of $150-600 \mathrm{mg}$. In the assessment of dose proportionalities using the power model, the $\mathrm{AUC}_{\text {last }}$ and $C_{\text {max }}$ of GLA5PR GLARS-NF1 exhibited dose proportionality in ranges of 150-600 and 150-450 mg, respectively. No clinically significant finding was observed in the safety evaluation after the administration of GLA5PR GLARS-NF1 tablets $(150,300,450$, and $600 \mathrm{mg})$ in the fed state.

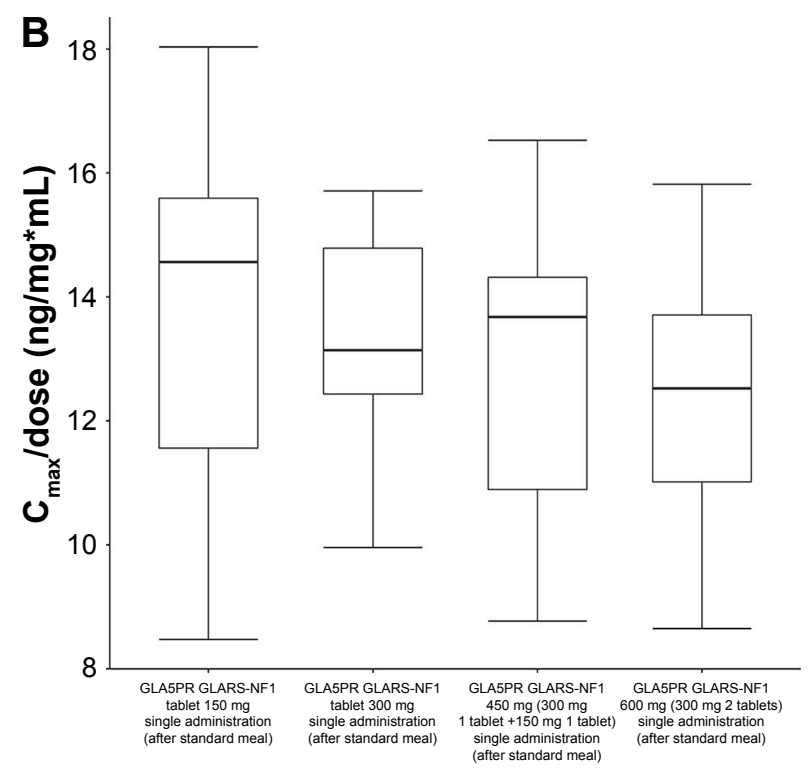

Figure 2 Box-whiskers-plots of pregabalin.

Notes: $(\mathbf{A}) \mathrm{AUC}_{\text {last }}$ /dose and (B) $C_{\max }$ /dose after oral GLA5PR GLARS-NFI 150, 300, 450, and $600 \mathrm{mg}$ administration. Median is indicated by line in the box. Interquartile range box represents the middle $50 \%$ of the data. Whiskers represent ranges of bottom and top $25 \%$ of data values excluding outliers.

Abbreviations: $A U C_{\text {last, }}$ area under the serum concentration-time curve from time zero to the time of the last measured concentration; $C_{\max }$ maximum serum concentration. 
Table 4 Assessment of dose proportionality for GLA5PR GLARS-NFI from I50 to $600 \mathrm{mg}$ using the power model ${ }^{\mathrm{a}}$

\begin{tabular}{l|l|l|l|l|l}
\hline Dependent variable & Model variable & Estimate $(\boldsymbol{\beta})$ & $\boldsymbol{P}$-value & $\mathbf{9 0 \%} \mathbf{C l}$ & Equivalent limits $^{\mathbf{b}}$ \\
\hline $\mathrm{AUC} C_{\text {last }}\left(\mathrm{h} \cdot \mathrm{ng}^{-1} \cdot \mathrm{mL}^{-1}\right)$ & $\ln ($ Dose $)$ & 1.0032 & $<0.000 \mathrm{I}$ & $0.9130-1.0935$ & $0.8390-1.1610$ \\
$C_{\max }(\mathrm{hg} / \mathrm{mL})$ & $\ln ($ Dose $)$ & 0.9246 & $<0.000 \mathrm{I}$ & $0.8241-1.0252$ & $0.8390-1.1610$ \\
\hline
\end{tabular}

Notes: aPower model: $\ln ($ pharmacokinetic $[\mathrm{PK}]$ parameter $)=\alpha+\beta * \ln ($ Dose $)+\varepsilon$. ${ }^{b}$ Equivalent limits: $\mathrm{I}+\{\ln (0.8) / \ln ($ dose ratio $)\}<\beta<\mathrm{I}+\{\ln (\mathrm{I} .25) / \ln ($ dose ratio $)\}$; Dose ratio: high dose/low dose.

Abbreviations: $\mathrm{AUC}_{\text {last }}$, area under the serum concentration-time curve from time zero to the time of the last measured concentration; $C_{\text {max }}$, maximum serum concentration.

A linear PK indicates that any concentration-time profiles normalized for dose or time are superimposable ${ }^{14}$ and the linear PK properties facilitate dose regimen adjustments in patients. One of the necessary conditions for a linear PK is dose proportionality, and its assessment is a major PK analysis conducted during clinical development. ${ }^{11}$ In a previous study, pregabalin showed linear PK properties at a dose range of 150-600 mg and a dose-response relationship was observed at this dose range. ${ }^{15}$ In the current study, GLA5PR GLARS-NF1, a newly developed controlled release (CR) formulation of pregabalin, showed dose proportionality and linearity at dose ranges of 150-450 $\mathrm{mg}$ and 150-600 $\mathrm{mg}$, respectively. Furthermore, the $\mathrm{AUC}_{\text {last }}$ of the GLA5PR GLARS-NF1 $600 \mathrm{mg}$ dose showed satisfactory dose proportionality, and the $C_{\max }$ slightly deviated from the lower limit value.

The study drug was administered after evening meal according to the label information of the marketed pregabalin, Lyrica. For pregabalin IR formulation (Lyrica), there was no clinically significant effect of food on the PKs of pregabalin, even though the absorption rate of pregabalin was decreased when administered with food, resulting in an approximately 25\%-35\% decrease in $C_{\max }$ and an approximately 3-hour increase in $T_{\max }$. In the drug label for IR formulation, the time of day of administration is not indicated for the regimen. ${ }^{16}$ On the contrary, for the pregabalin CR formulation, the $\mathrm{AUC}_{\text {inf }}$ ratios of the fed states with medium caloric contents (600-750 calories) and low caloric contents (400-500 calories) over the fast states were $142.02 \%$ and $129.58 \%$, respectively. ${ }^{17}$ In the drug label for $\mathrm{CR}$ formulation, drug administration is recommended after evening meal.

Because the safety of subjects in the study was a concern, the study drug was administrated in the evening. The most commonly reported AEs for pregabalin were dizziness and sleepiness in healthy subjects. ${ }^{1}$ Subjects in this study took pregabalin after dinner to reduce these AEs and, thereby, its safety improved. Among the 38 subjects who received the investigational products, $10(26.3 \%)$ experienced a total of 17 AEs (six cases of dizziness; two cases each of blurred vision, white blood cells in the urine, dysarthria, and

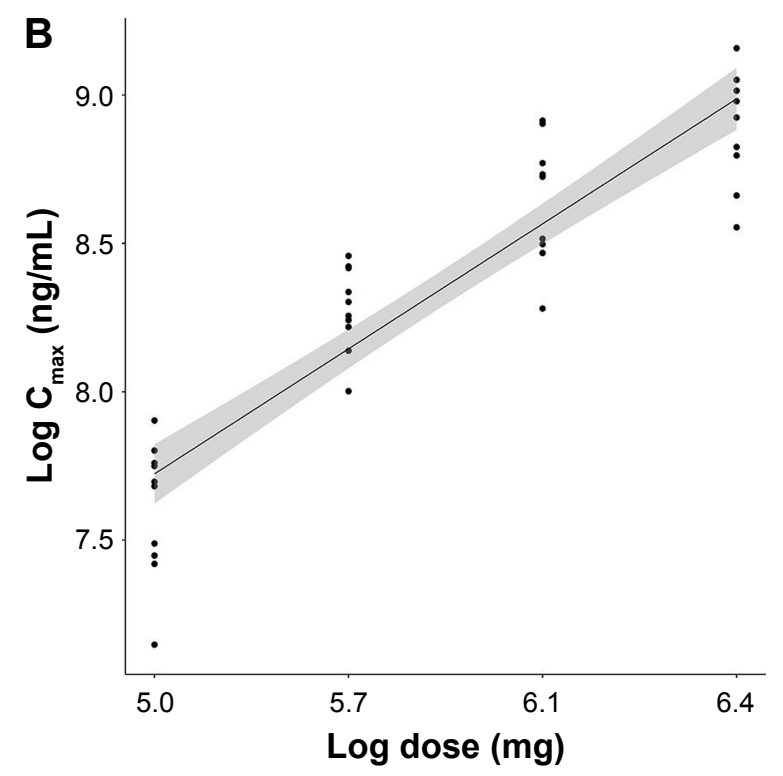

Figure 3 Regression plot of pregabalin.

Note: $(\mathbf{A}) \log \left(A \cup C_{\text {last }}\right)$ and $(B) \log \left(C_{\max }\right)$.

Abbreviations: $A \cup C_{\text {last }}$, area under the serum concentration-time curve from time zero to the time of the last measured concentration; $C_{\text {max }}$ maximum serum concentration. 
Table 5 Adverse events in subjects for GLA5PR GLARS-NFI from 150 to $600 \mathrm{mg}$ administrations

\begin{tabular}{l|l|l|l|l}
\hline $\begin{array}{l}\text { System organ class } \\
\text { preferred term }\end{array}$ & $\begin{array}{l}\text { I50 } \mathbf{~ m g} \\
(\mathbf{n}=\mathbf{I 0})\end{array}$ & $\begin{array}{l}\mathbf{3 0 0} \mathbf{~ m g} \\
(\mathbf{n}=\mathbf{I 0})\end{array}$ & $\begin{array}{l}\mathbf{4 5 0} \mathbf{~ m g} \\
(\mathbf{n}=\mathbf{9})\end{array}$ & $\begin{array}{l}\mathbf{6 0 0} \mathbf{~ m g} \\
(\mathbf{n}=\mathbf{9})\end{array}$ \\
\hline Total & $\mathrm{I}(\mathrm{I})$ & $3(3)$ & $2(4)$ & $4(9)$ \\
Eye disorders & $0(0)$ & $0(0)$ & $\mathrm{I}(\mathrm{I})$ & $\mathrm{I}(\mathrm{I})$ \\
$\quad$ Vision blurred & $0(0)$ & $0(0)$ & $\mathrm{I}(\mathrm{I})$ & $\mathrm{I}(\mathrm{I})$ \\
Gastrointestinal disorders & $0(0)$ & $0(0)$ & $0(0)$ & $\mathrm{I}(\mathrm{I})$ \\
$\quad$ Nausea & $0(0)$ & $0(0)$ & $0(0)$ & $\mathrm{I}(\mathrm{I})$ \\
Investigations & $\mathrm{I}(\mathrm{I})$ & $2(2)$ & $0(0)$ & $0(0)$ \\
Blood bilirubin increased & $0(0)$ & $\mathrm{I}(\mathrm{I})$ & $0(0)$ & $0(0)$ \\
White blood cells urine & $\mathrm{I}(\mathrm{I})$ & $\mathrm{I}(\mathrm{I})$ & $0(0)$ & $0(0)$ \\
positive & & & & \\
Nervous system disorders & $0(0)$ & $0(0)$ & $2(3)$ & $4(7)$ \\
$\quad$ Dizziness & $0(0)$ & $0(0)$ & $2(2)$ & $4(4)$ \\
Dysarthria & $0(0)$ & $0(0)$ & $\mathrm{I}(\mathrm{I})$ & $\mathrm{I}(\mathrm{I})$ \\
Headache & $0(0)$ & $0(0)$ & $0(0)$ & $2(2)$ \\
Vascular disorders & $0(0)$ & $\mathrm{I}(\mathrm{I})$ & $0(0)$ & $0(0)$ \\
Hypertension & $0(0)$ & $\mathrm{I}(\mathrm{I})$ & $0(0)$ & $0(0)$ \\
\hline
\end{tabular}

Note: Data are represented as number of subjects (number of cases).

headache; and one case each of increased blood bilirubin levels, nausea, and hypertension). There were no significant differences in $\mathrm{AE}$ incidence between the treatment groups, and no clinically significant findings were observed in the safety evaluations.

The current study had some limitations that are worth mentioning. For instance, the study was conducted with healthy male volunteers using a parallel study design, and patients might show different PK properties from those of healthy subjects because of factors such as disease progression or the administration of concomitant drugs. A crossover study design was adopted in numerous dose-proportional PK studies to reduce the effect of interindividual variability. However, the parallel study designs were also chosen for numerous dose-proportional studies. In a previous report, a total of $34 \%$ of approximately 150 clinical studies were performed with a parallel study design. ${ }^{11}$ On the contrary, gender was one of the major factors affecting the PK and pharmacodynamics of drugs. ${ }^{18,19}$ However, no clinically significant gender difference was observed in the population PKs of pregabalin. ${ }^{16}$ Meanwhile, the average age of the study subjects was 25 years. The oral clearance of pregabalin has shown trends to decrease with increasing age, and it was considered to be related to decreased creatinine clearance. ${ }^{16}$ Further evaluation of dose proportionality in a wide ranges of ages including elderly patients would be helpful for determining the comprehensive PK characteristics of pregabalin.

\section{Conclusion}

GLA5PR GLARS-NF1 exhibited dose proportionality in the range of $150-450 \mathrm{mg}$. Doses ranging from 150 to $600 \mathrm{mg}$
GLA5PR GLARS-NF1 were well-tolerated in the healthy subjects.

\section{Acknowledgments}

The plasma pregabalin concentration was analyzed at the Biocore Corporation (Seoul, Republic of Korea). This work was supported by GL Pharm Tech Corporation (Seongnam, Republic of Korea; 201713280000).

\section{Author contributions}

All authors contributed toward data analysis, drafting and critically revising the paper, gave final approval of the version to be published, and agree to be accountable for all aspects of the work.

\section{Disclosure}

The authors report no conflicts of interest in this work.

\section{References}

1. Finnerup NB, Jensen TS. Clinical use of pregabalin in the management of central neuropathic pain. Neuropsychiatr Dis Treat. 2007;3(6): 885-891.

2. Verma V, Singh N, Singh Jaggi A. Pregabalin in neuropathic pain: evidences and possible mechanisms. Curr Neuropharmacol. 2014; 12(1):44-56.

3. Tassone DM, Boyce E, Guyer J, Nuzum D. Pregabalin: a novel gammaaminobutyric acid analogue in the treatment of neuropathic pain, partialonset seizures, and anxiety disorders. Clin Ther. 2007;29(1):26-48.

4. Product Information. LYRICA Oral Capsules os, Pregabalin Oral Capsules, Oral Solution. Pfizer, Inc. (Per). New York, NY: FDA; 2012.

5. Bockbrader HN, Wesche D, Miller R, Chapel S, Janiczek N, Burger P. A comparison of the pharmacokinetics and pharmacodynamics of pregabalin and gabapentin. Clin Pharmacokinet. 2010;49(10):661-669.

6. Cappuzzo KA. Treatment of postherpetic neuralgia: focus on pregabalin. Clin Interv Aging. 2009;4:17-23.

7. Stacey BR, Swift JN. Pregabalin for neuropathic pain based on recent clinical trials. Curr Pain Headache Rep. 2006;10(3):179-184.

8. Cramer JA, Glassman M, Rienzi V. The relationship between poor medication compliance and seizures. Epilepsy Behav. 2002;3(4):338-342.

9. Park JS, Shim JY, Park JS, Choi YW, Jeong SH. A novel three-layered tablet for extended release with various layer formulations and in vitro release profiles. Drug Dev Ind Pharm. 2011;37(6):664-672.

10. Shah GR, Ghosh C, Thaker BT. Determination of pregabalin in human plasma by electrospray ionisation tandem mass spectroscopy. $J A d v$ Pharm Technol Res. 2010;1(3):354-357.

11. Sheng Y, He Y, Huang X, Yang J, Wang K, Zheng Q. Systematic evaluation of dose proportionality studies in clinical pharmacokinetics. Curr Drug Metab. 2010;11(6):526-537.

12. Hummel J, Mckendrick S, Brindley C, French R. Exploratory assessment of dose proportionality: review of current approaches and proposal for a practical criterion. Pharm Stat. 2009;8(1):38-49.

13. Gilman AG, Rall TW, Nies AS. Goodman and Gilman's The Pharmacological Basis of Therapeutics. 8th ed. New York, NY: Pergamon Press; 1990.

14. Ludden TM. Nonlinear pharmacokinetics: clinical Implications. Clin Pharmacokinet. 1991;20(6):429-446.

15. Ben-Menachem E. Pregabalin pharmacology and its relevance to clinical practice. Epilepsia. 2004;45 (Suppl 6):13-18.

16. Lyrica $^{\circledR}$ Drug Label updated 05/Mar/2018. FDA Approved Drug Products. Available from: https:/www.accessdata.fda.gov/drugsatfda_docs/ label/2016/021446s032,022488s011lbl.pdf. Accessed March 10, 2018. 
17. Chew ML, Plotka A, Alvey CW, et al. Pharmacokinetics of pregabalin controlled-release in healthy volunteers: effect of food in five single-dose, randomized, clinical pharmacology studies. Clin Drug Investig. 2014; 34(9):617-626.

18. Soldin OP, Mattison DR. Sex differences in pharmacokinetics and pharmacodynamics. Clin Pharmacokinet. 2009;48(3):143-157.
19. Bigos KL, Pollock BG, Stankevich BA, Bies RR. Sex differences in the pharmacokinetics and pharmacodynamics of antidepressants: an updated review. Gend Med. 2009;6(4):522-543.

\section{Publish your work in this journal}

Drug Design, Development and Therapy is an international, peerreviewed open-access journal that spans the spectrum of drug design and development through to clinical applications. Clinical outcomes, patient safety, and programs for the development and effective, safe, and sustained use of medicines are the features of the journal, which has also been accepted for indexing on PubMed Central. The manuscript management system is completely online and includes a very quick and fair peer-review system, which is all easy to use. Visit http://www.dovepress.com/testimonials.php to read real quotes from published authors.

Submit your manuscript here: http://www.dovepress.com/drug-design-development-and-therapy-journal 